\title{
NOTES AND OBSERVATIONS ON THE ROSE STEM GIRDLER (AGRILUS CUPRESCENS MÉNÉTRIÉS) (INSECTA: COLEOPTERA: BUPRESTIDAE) IN SOUTHERNALBERTAAND SASKATCHEWAN
}

DAVID J. LARSON, Box 56, Maple Creek, SK, SON 1N0;

E-mail: <mareeba1@sasktel.net>

The rose stem girdler (Fig. 1) is a Palaearctic metallic wood-boring beetle (Coleoptera: Buprestidae) that has a wide range extending from Europe east into Siberia. In North America, it was first discovered in New Jersey. Within its range, this species varies considerably in color, punctation, and size. Because of this wide range and variation, it is not surprising that species, subspecies,

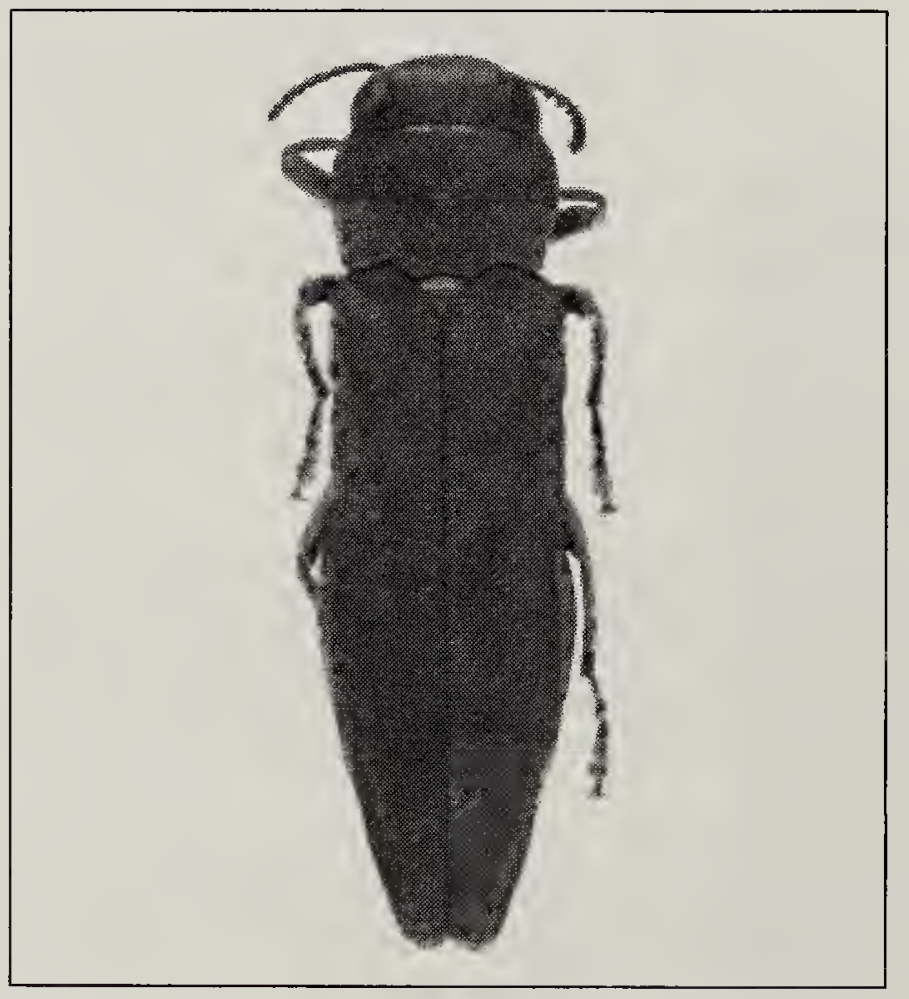

Figure 1. Adult rose stem girdler, dorsal aspect, collected $16 \mathrm{~km}$ south of Maple Creek, SK. Beetle length = $5.5 \mathrm{~mm}$.

David Larson and varieties have been variously recognized and that there has been considerable confusion. nomenclatural North American populations have been referred to as Agrilus aurichalceus Redtenbacher (see Bright for nomenclatural history in North America ${ }^{1}$ ), but recently, Jendek showed that $A$. aurichalceus is a junior synonym of $A$. cuprescens; ${ }^{3}$ thus, the valid name for the species is Agrilus cuprescens (Ménétriés, 1832).

The rose stem girdler was first recorded from the prairies in $2003,{ }^{4}$ where at that time it was causing mortality in wild roses, namely Rosa acicularis Lindl. and $R$. woodsi Lindl., as well as in larger canes of $R$. arkansana Porter. It was not known how widespread the species was, but it is likely that the girdler reached the prairies through natural dispersal from the east rather than as an isolated introduction into SW Saskatchewan. The occurrence in native roses locally rather than in cultivated roses supports this. No subsequent comprehensive survey of the range of the species has been made, but during my travels I have inspected rose stands for girdled canes. Girdled, dead canes persist in 
a stand for several years and can be observed year round; they are therefore good markers indicating the presence of girdlers. Since 2003, I have found girdled stems from the South Saskatchewan River south to the US border, throughout the Great Sand Hills, from Swift Current to Medicine Hat, Bow Island, Taber, and Lethbridge, and along the Cypress Hills from Duncairn Reservoir to Elkwater. This distribution simply reflects my travels; the species is likely more widespread.

Infestation of either dead or live canes is easily determined by removing a strip of bark from the lower half to two-thirds of the cane to expose the spiral larval tunnel. During the growing season, infected canes start to show effects of larval tunnelling by the leaves turning red prematurely, usually from mid-August onwards, which in dry years may be mistaken for drought effects. These leaves remain on the infested stems over winter and conspicuously mark recently killed stems, as can be readily confirmed by stripping off the bark to expose the spiral tunnel.

Bright reported that there was one generation a year and that after having completed feeding, a larva tunnels into the pith where it spends the winter and then pupates the following spring. ${ }^{1}$ । previously reported not finding overwintering larvae in infected stems and speculated on whether they left the stems to overwinter in the soil. ${ }^{4}$ However, I have subsequently found a few overwintering larvae in stems (Fig. 2 ), and they appeared viable even after the very cold winter of 2008-09.

Nevertheless, overwintering larvae are absent from the vast majority of stems, indicating either high larval mortality or that many larvae do overwinter elsewhere. A careful study of the life history of the species, with emphasis on causes and extent of mortality, would be most interesting. It is unlikely that natural parasites came with the species from Europe, but such tunnelling insects are often attacked by a suite of hymenopteran (wasp) parasitoids. The fact that such parasitoids are usually more specific to the habitat type than to the taxonomic affinity of their host ${ }^{2}$ suggests that stem girdlers may have attracted a community of parasitoids that could be a significant cause of mortality. I have not noticed any sign of bark being ripped away from over mines, suggesting that predators, especially birds, do not seem to have discovered the larvae.

Generally, roses can be pruned with the stem branching below the point where it is severed; however, when a stem is girdled, the entire stem dies back to ground level rather than simply dying beyond the point of being girdled. This response means that within

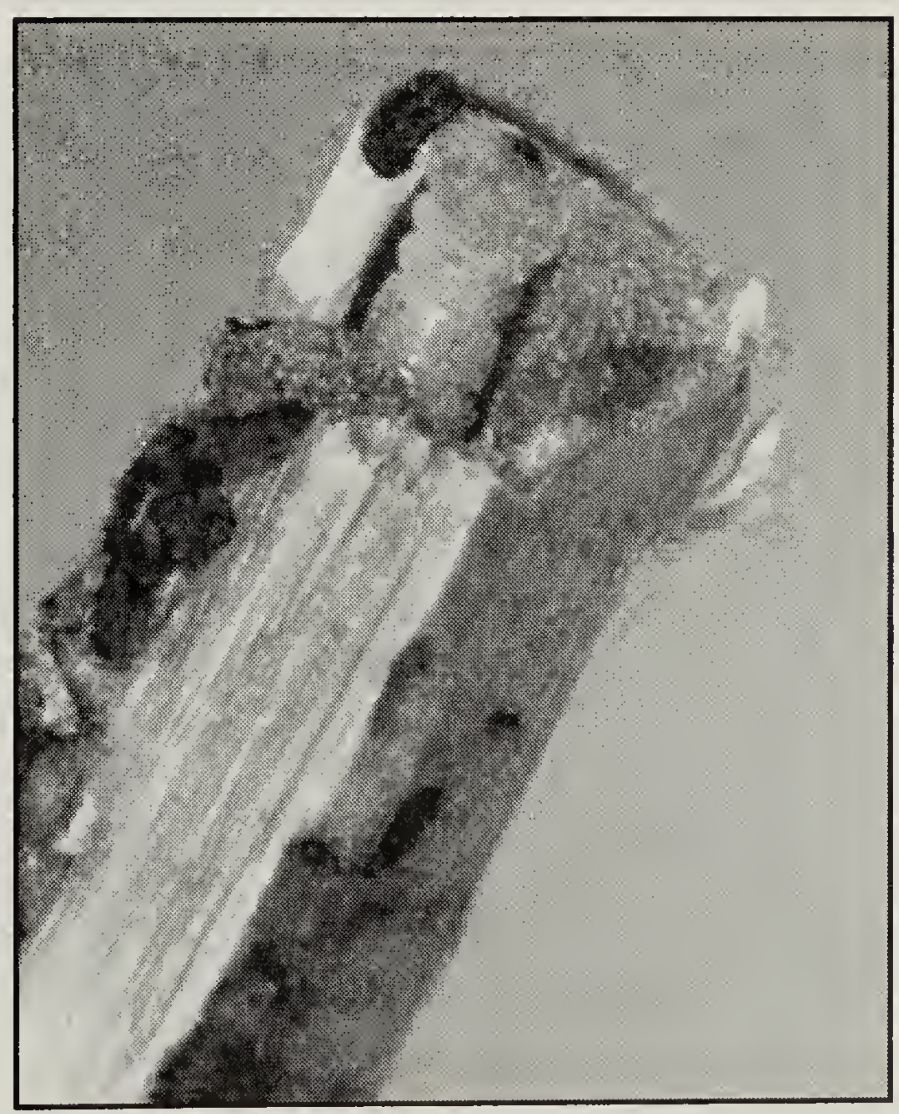

Figure 2. Anterior half of body of the overwintering larva of the rose stem girdler in the pith of a rose. Specimen collected February 2009. 
stands, those stems that are infested die. These are generally larger and older stems, and over several years, the result is a reduction in density and overall size of living stems, thus stands become lower and more open.

I previously made some speculations about the effects of the rose stem girdler on prairie plant communities. ${ }^{4}$ Specifically, patches of dense shrubs would be reduced in size and density, and the reduction in the abundance of roses would allow grazing animals, especially cattle, to graze into and further reduce this habitat type. Unfortunately, I have no quantitative data on changes in the roses and associated plants within this region, although anecdotal observations provide some indication of what might be happening. I often visit the Great Sand Hills, parking on the access roads and walking to the active dune areas. Ten years ago, these walks required one to wear heavy clothing to protect against rose thorns, and the route involved following cattle trails: In more recent years, access has generally been over closely grazed grass, with the roses reduced to small patches of low, open bushes (Figure 3). As the roses died, cattle pushed into the patches, opening them up. Initially, there was bloom of various forbs, but the dominant vegetation seems to be reverting primarily to various grasses.

Riparian areas also show effects from loss of roses. On our farm, $16 \mathrm{~km}$ south of Maple Creek, roses once formed dense tangles in the riparian zone and in aspen clones. Many stems exceeded $2 \mathrm{~m}$ in height and some reached $3 \mathrm{~m}$ (Fig. 4). In 2000, it was very difficult to force oneself along a fenceline through an aspen stand because of the dense roses that equalled the fence in height. However, by the winter of 20089 , it was possible to string sheep fencing along this fence-line, as the roses had collapsed into dead canes (Fig. 5). The dominant understory vegetation had become Smooth Brome Grass (Bromus inermus).

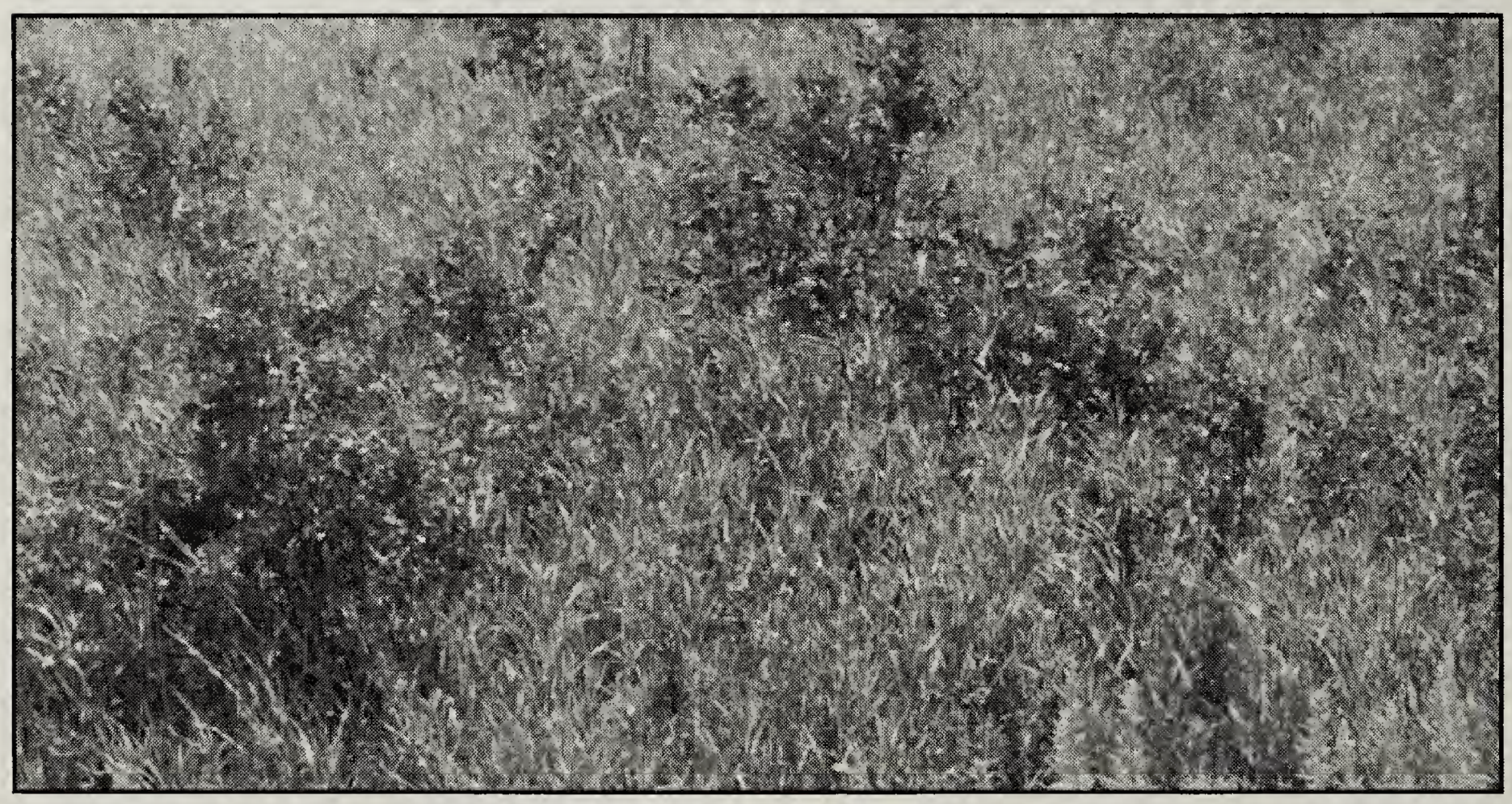

Figure 3. A dying patch of roses in sandhills $7 \mathrm{~km}$ west of Piapot, SK. Plants with reddish foliage (seen as dark patches in this photo) have been girdled and will die. A few bare and broken stems that were killed in previous years are barely visible, but most stems break or collapse the year after being killed and become obscured by grass incursion. This stand was probably almost a monoculture before stem girdler caused mortality. 


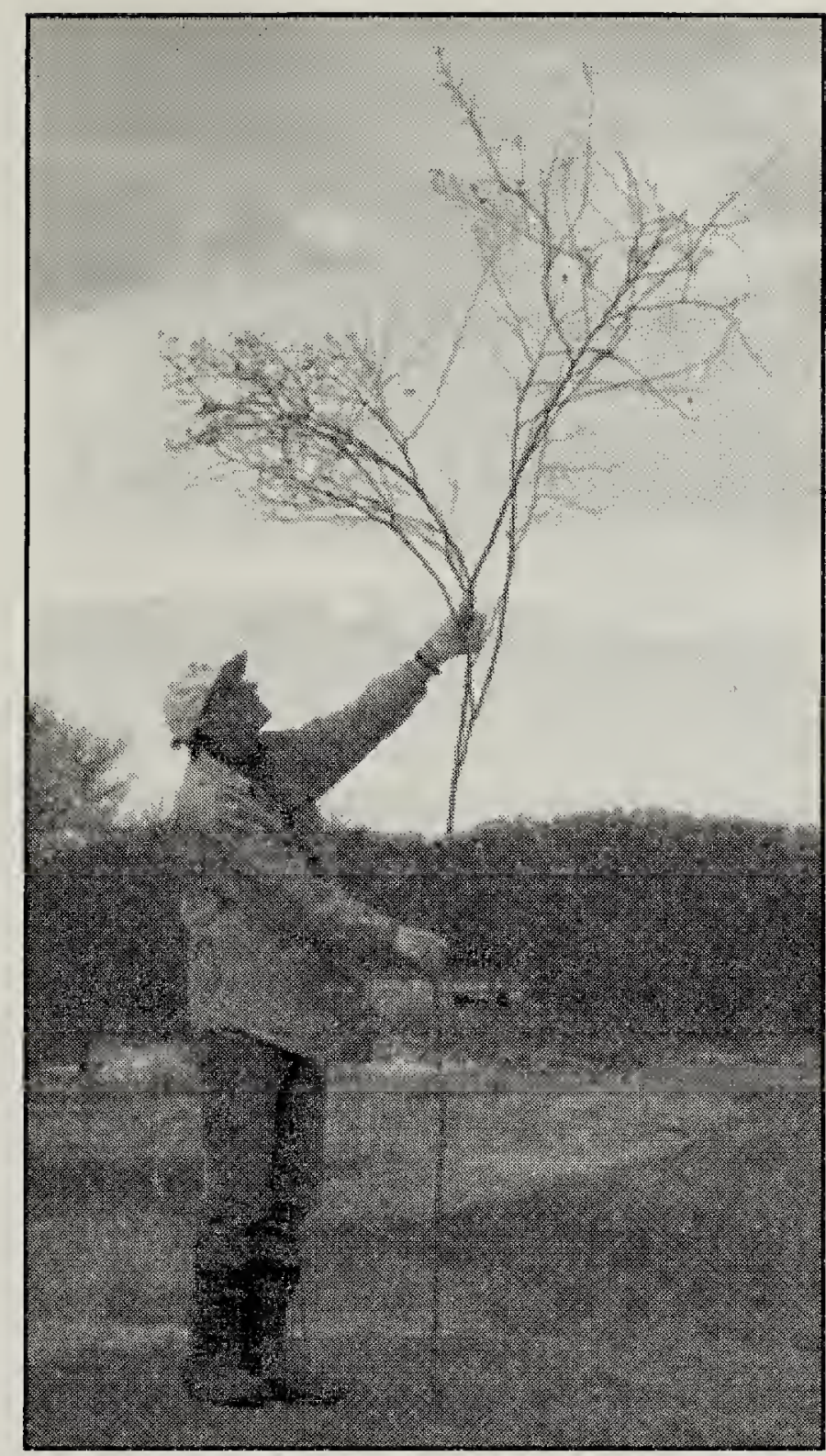

Figure 4. One of the last of the tall rose stems along Fleming Creek, $16 \mathrm{~km}$ south of Maple Creek. This stem bloomed and set fruit in the summer of 2008 but was dead in winter 20089 , having been girdled in several places. Maximum height is $3.7 \mathrm{~m}$.

It is likely that a variety of ecological ramifications of the rose stem girdler will be observed. Unfortunately, the opportunity to carefully document the effects of the beetle in southern Saskatchewan, and probably also southern Alberta, has been missed. However, the species may still be spreading, and naturalists in areas that presently have healthy stands of roses have an opportunity to monitor and document the impact of the species as its range expands.

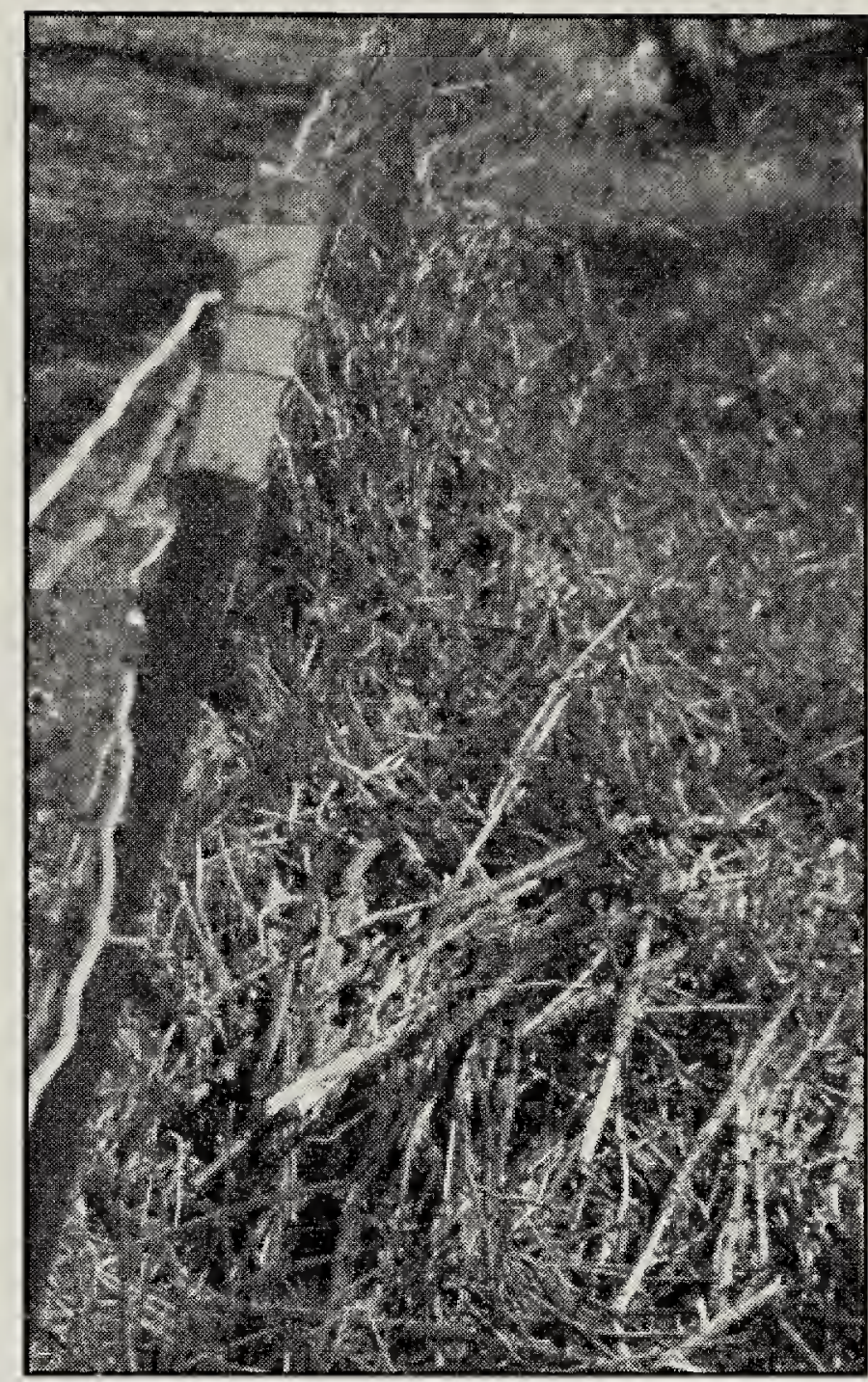

Figure 5. Dead rose stems still supported by a fence, $16 \mathrm{~km}$ south of Maple Creek, May, 2009. Virtually all stems were attacked by rose stem girdler larvae as indicated by the presence of one or more spiral mines etched into each stem somewhere along its length. Stems killed in the previous year are recognizable as they still bear dry, brown leaves.

1. BRIGHT, D.E. 1987. The insects and arachnids of Canada. Part 15. The metallic wood-boring beetles of Canada and Alaska (Coleoptera: Buprestidae). Research Branch, Agriculture Canada, Publication 1810.

2. GIBSON, G.A.P., J.T. HUBER, and J.B. WOOLLEY. 1997. Annotated keys to the genera of Nearctic Chalcidoidea (Hymenoptera). NRC Research Press, Ottawa, ON.

3. JENDEK, E. 2003. Revision of Agrilus cuprescens (Ménétriés, 1832) and related species (Coleoptera: Buprestidae). Zootaxa 317:1-22.

4. LARSON, D. J. 2003. The rose stem girdler (Agrilus aurichalceus Redtenbacher) (Insecta: Coleoptera: Bupresridae), a new threat to prairie roses. Blue Jay 61(3):176-178. 